\title{
On the Development of Shell Buckling Knockdown Factors for Stiffened Metallic Launch Vehicle Cylinders
}

\author{
Mark W. Hilburger* \\ NASA Langley Research Center, Hampton, Virginia, 23681, USA \\ (Please address all correspondence to Mark W. Hilburger, Mail Stop 190, \\ NASA Langley Research Center, Hampton VA 23681-2199 \\ Mark.W.Hilburger@nasa.gov)
}

\begin{abstract}
:
Proposed paper to be presented at the 59th AIAA/ASME/ASCE/AHS/ASC Structures, Structural Dynamics, and Materials Conference with AIAA SciTech 2018

January 8-12, 2018

Kissimmee, FL
\end{abstract}

\section{Introduction}

From the 1920s to the early 1970s, many shell buckling experiments were conducted in an effort $\Gamma$ to understand the complex buckling behavior exhibited by thin-walled cylindrical shells, to provide data to correlate with new shell stability theories, and provide design guidelines. Typically, the experiments yielded buckling loads that were substantially lower than the corresponding analytical predictions, which were based on simplified linear bifurcation analyses of geometrically perfect shells with nominal dimensions and idealized boundary conditions. The seminal works by von Kármán and Tsien ${ }^{1}$, by Donnell and $\mathrm{Wan}^{2}$, and by Koiter ${ }^{3}$ identified small deviations from the idealized geometry of a shell, known as initial geometric imperfections, as a primary source of the discrepancy between corresponding analytical predictions and experimental results. However, the computational tools and capabilities at that time could not perform the nonlinear analyses needed to assess the effects of these imperfections on the buckling behavior of thin-walled shells. Thus, buckling design allowables were determined by establishing lower bounds to test data. Specifically, empirical design factors, that have become known as knockdown factors, were determined and were to be used in conjunction with linear bifurcation analyses for simply supported shells; that is, these empirical factors were used to "knock down" the value of the unconservative simplified analytical prediction. This approach to shell buckling design has proved satisfactory for most design purposes and remains prominent in industry practice, as evidenced by the extensive use of the NASA space vehicle design criteria and recomendations. ${ }^{4-8}$ Unfortunately, the current design guidelines have not been updated since they were first published in the late 1960s and may not be able to take full advantage of modern materials, precision manufacturing processes, and new structural concepts.

\footnotetext{
* Senior Research Engineer, Structural Mechanics and Concepts Branch, Hampton, VA, 23681,
} USA, Senior Member AIAA. 
Recently, however, new research activities are attempting to provide updated buckling design factors (a.k.a. knockdown factors, KDFs) and design guidelines for buckling-critical shells and show significant promise and technical merit. ${ }^{9-12}$ If successful, the results from these activities may likely form the basis for the next generation of shell buckling design factors and recommendations. One such activity is the NASA Shell Buckling Knockdown Factor (SBKF) Project. SBKF was established in 2007 by the NASA Engineering and Safety Center (NESC) with the goal to develop less-conservative, robust shell buckling KDFs and design recommendations for metallic and composite launch vehicle structures on the NASA Space Launch System (SLS). Preliminary design studies indicate that implementation of these new KDFs can enable significant reductions in mass in these vehicles and can help mitigate some of NASA's launch vehicle development and performance risks. ${ }^{13-15}$ In addition, it is expected that the results from this project will provide high-fidelity estimates of structural performance and robustness, and over time, help reduce the reliance on large-scale structural testing.

The development of new analysis-based KDFs for integrally-stiffened SLS-like metallic cylinders will be presented in the proposed paper. First, the cylinder designs are described and models and analysis methods used to calculate the analysis-based KDFs are discussed in detail. Then, new KDFs for integrally-stiffened metallic cylinders with axial weld lands will be presented. Finally, results from a simulated design cycle will be presented to illustrate the use of the new KDFs. This abstract provides sample content from the full paper.

\section{Stiffened Cylinder Designs}

Analysis-based KDFs for orthogrid-stiffened and isogrid-stiffened metallic cylinder with axial welds are being developed by SBKF for SLS-like launch vehicle designs. SLS Core Stage (CS) cylinders are 27.5-feet in diameter and are constructed from eight integrally-stiffened, curvedpanel segments ( $45^{\circ}$ arc segments) that are friction-stir welded together to form a complete cylinder (see illustration in Fig.1). For all designs considered, the stiffeners were located on the inner surface of the shell wall. The design space for the KDFs development was defined based on NASA launch vehicle cylinder designs from the Ares 1 Upper Stage (US), Ares 5 Core Stage (CS), and the Space Launch System (SLS) CS, and included orthogrid- and isogrid-stiffened concepts. The design space will be defined in more detail in the proposed paper. The orthogrid and isogrid construction and axial weld lands are described in this section.

The orthogrid stiffener pattern and design variables are shown in Fig. 2, where $t$ is the skin thickness, $t_{s}$ is the stringer thickness, $t_{r}$ is the ring thickness, $H$ is the total stiffener height, $b_{s}$ is the stringer spacing, and $b_{r}$ is the ring spacing. The isogrid stiffener pattern and design variables are shown in Fig. 3, where $t$ is the skin thickness, $H$ is the total stiffener height, $b$ is the stiffener thickness, and $a$ is the stiffener length. 


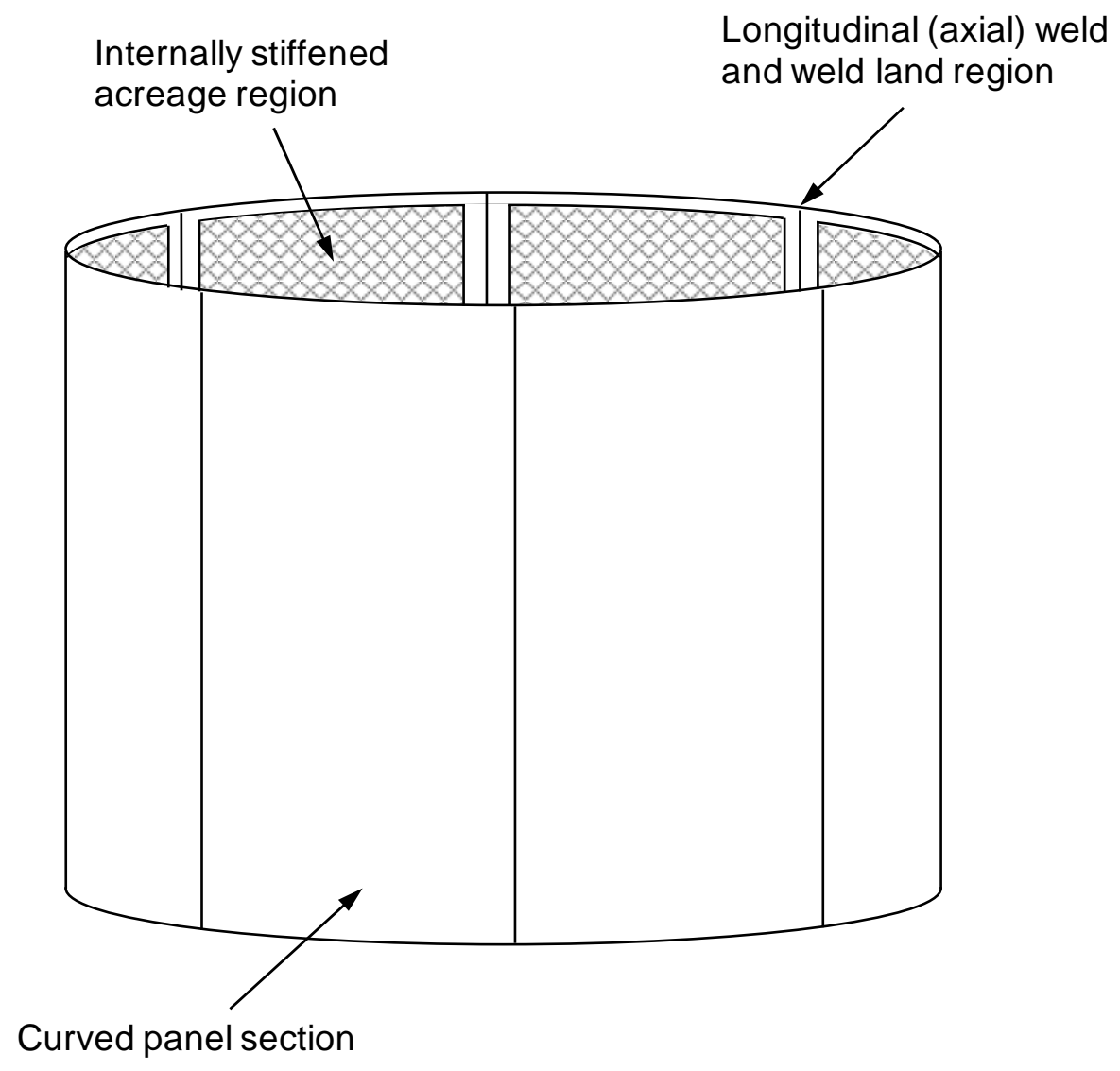

Figure 1. Cylinder description.

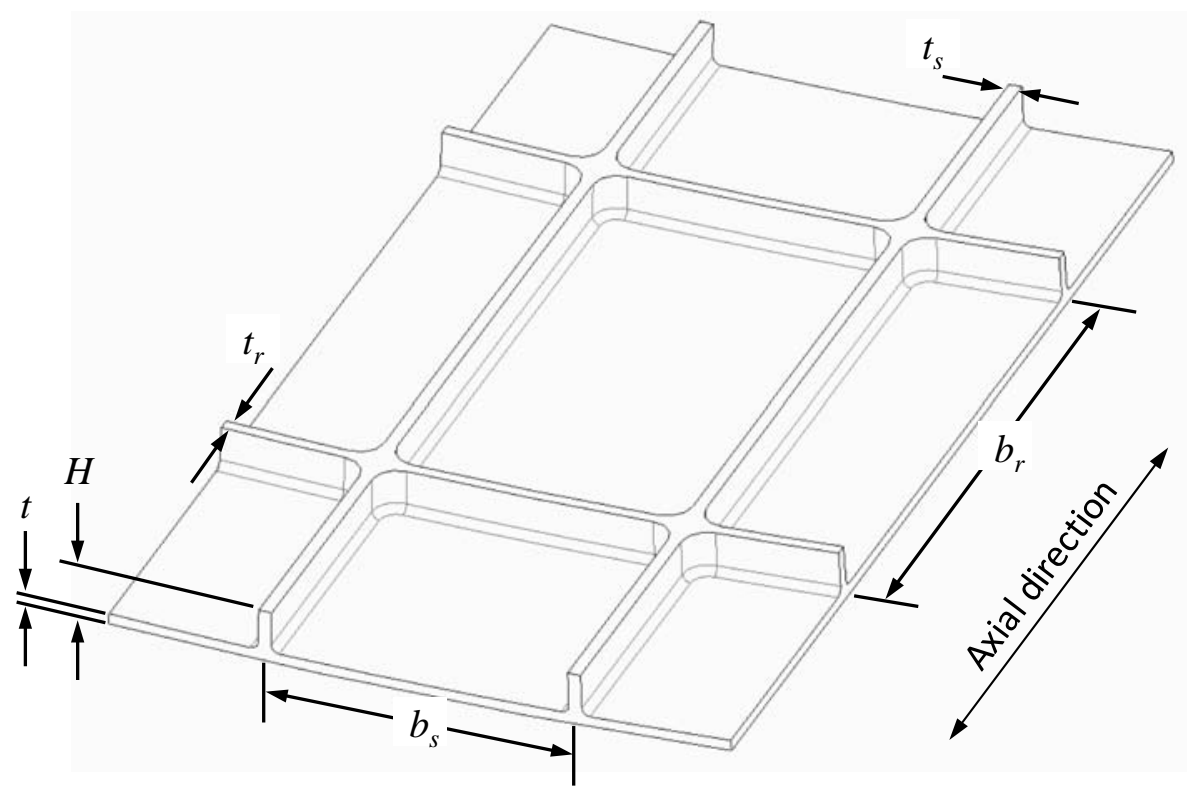

Figure 2. Orthogrid geometry definition. 


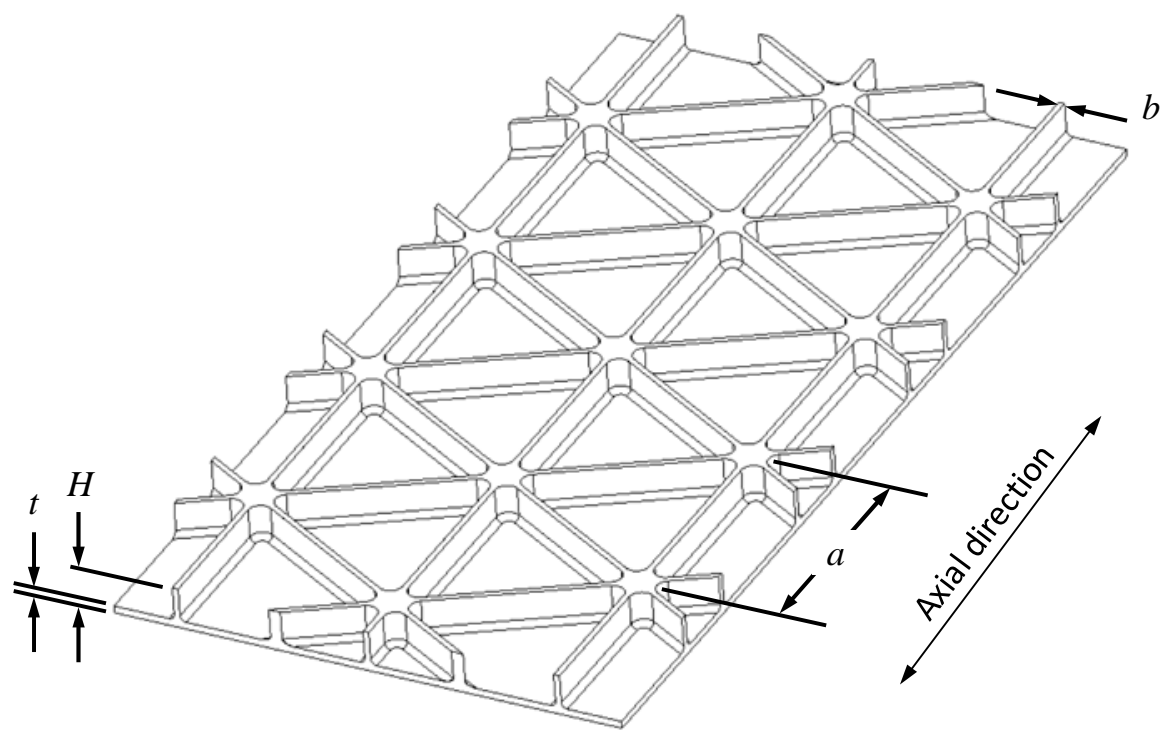

Figure 3. Isogrid geometry definition.

Axial and circumferential weld land designs were developed based on a space shuttle external tank (ET) design (see Fig. 4a) and on a proposed SLS CS design (see Fig. 4b). The ET design includes a transition region in which the axial and circumferential stiffeners gradually taper down into the monocoque weld land region and the skin thickness is increased. The SLS-type circumferential weld land and transition region have many of the same features as the ET design, however, the circumferential stiffeners in the SLS design do not gradually taper down into the axial weld land region, rather the stiffeners terminate at an axial stiffener adjacent to the weld land. This type of design is commonly referred to as a picture frame design.

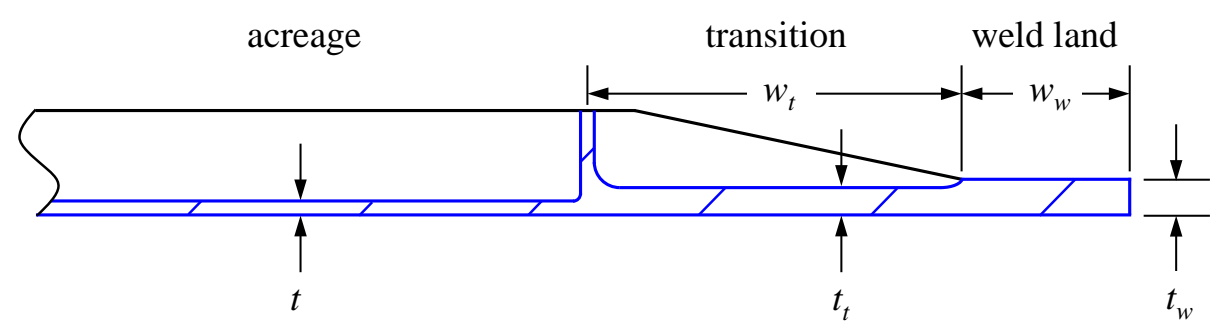

a) Typical acreage and weld land design with a tapered stiffener transition.

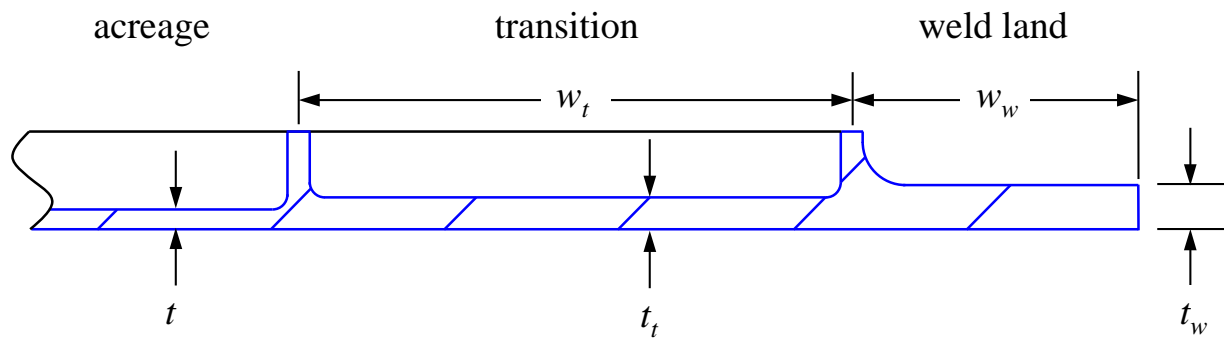

b) Typical acreage and weld land design with a "picture frame” stiffener transition.

Figure 4. Weld land geometry definition (shown in shown in the flat condition used for machining). 


\section{KDF Assumptions, Definitions and Development Approach}

Analysis-based knockdown factors are becoming a viable replacement for the test-based knockdown factors used currently. More specifically, improved nonlinear structural analysis tools and improved theories of elastic stability and imperfection sensitivity in shell structures are enabling high-fidelity predictions of the buckling response of thin-walled compression-loaded cylindrical shells. ${ }^{16}$ These high-fidelity predictions and analysis tools are the foundation for the new analysis-based knockdown factors being developed by SBKF. A brief description of the KDF assumptions and development approach are presented next.

\section{Structural configuration}

Several general assumptions on the structural configuration were made based on preliminary SLS CS cylinder designs and include the geometry, material properties, boundary conditions, and loads.

These assumptions were as follows:

1. The cylinder is $27.5-\mathrm{ft}$ in diameter and 27.5 - $\mathrm{ft}$ long.

2. The cylinder is constructed from eight integrally-stiffened, curved-panel segments that are joined together along eight axial weld lands.

3. The cylinder is supported by some type of stiff ring at the upper and lower end that constrains radial and tangential displacements at the ends.

4. The material is isotropic and linear-elastic throughout the prebuckling response (i.e., no material yielding prior to buckling).

5. The cylinder is subjected to axial compression load or combined axial compression and internal pressure.

\section{KDF assumptions}

SBKF has developed KDFs that account for the following effects:

1. Geometric imperfection

2. Loading non-uniformity associated with manufacturing and fit-up tolerances (a.k.a. loading imperfection)

3. Stiffener pattern (i.e., orthotropy)

4. Axial welds and weld lands

5. Local skin pocket buckling (buckling of skin between stiffeners)

\section{Development approach}

One of the key and unique attributes of the new analysis-based factor development approach is that individual design effects, such as the ones listed in the previous section, can be isolated analytically, and accounted for explicitly in the design factors.

This approach enabled the development of a hierarchy of KDFs that can be tailored to account for selected design features and effects that are relevant for the design of interest. Furthermore, the KDFs can evolve as the design matures and more information becomes available during the design cycle. This hierarchical design approach and the corresponding KDFs will be discussed in detail in the full paper. In addition, results from a simulated design cycle will be presented that illustrate the tailorability and evolvability of the new KDFs during the design process. 


\section{Concluding Remarks}

The NASA SBKF project has developed new analysis-based shell buckling knockdown factors for modern integrally-stiffened metallic launch vehicle structures. These new knockdown factors are based on the results from experimentally validated high-fidelity finite element analyses. These new KDFs account for the effects of geometric and loading imperfections, stiffener pattern orthotropy, longitudinal welds, and combined mechanical and internal pressure loads. In addition, these factors have been developed such that they can be tailored and evolve as the design matures during the design cycle.

\section{Acknowledgments}

This work was conducted as part of the NASA Engineering and Safety Center (NESC) Shell Buckling Knockdown Factor Project, NESC Assessment \#:07-010-E.

\section{References}

1. von Kármán, T., and Tsien, H. S., "The Buckling of Thin Cylindrical Shells Under Axial Compression," Journal of the Aeronautical Science, Vol. 8, No. 8, June 1941, pp. 303-312.

2. Donnell, L. H., and Wan, C. C., "Effect of Imperfections on Buckling of Thin Cylinders and Columns Under Axial Compression," Journal of Applied Mechanics, Vol. 17, No. 1, March 1950, pp. 73-83.

3. Koiter, W. T., "On the Stability of Elastic Equilibrium. (in Dutch),” H. J. Paris, Amsterdam, Holland, 1945, translation available as AFFDL-TR-70-25, February, 1970, Wright-Patterson Air Force Base.

4. "Buckling of Thin-Walled Circular Cylinders," NASA Space Vehicle Design Criteria, NASA SP8007, September 1965 (Revised 1968).

5. “Buckling of Thin-Walled Truncated Cones,” NASA Space Vehicle Design Criteria, NASA SP-8019, September 1968.

6. "Buckling of Thin-Walled Doubly Curved Shells,” NASA Space Vehicle Design Criteria, NASA SP8032, August 1969.

7. Peterson, James P., "Buckling of Stiffened Cylinders in Axial Compression and Bending - A Review of Test Data," NASA TN D-5561, 1969.

8. “Isogrid Design Handbook,” NASA CR-124075, February 1973.

9. Hilburger, M.W., Nemeth, M.P., Starnes, J.H.,Jr., "Shell Buckling Design Criteria Based on Manufacturing Imperfection Signatures,” AIAA Journal, vol. 44, no. 3, March 2006.

10. Huhne, C., Rolfes, R., Breitbach, E., and Tessmer, J., "Robust Design of Composite Cylindrical Shells Under Axial Compression - Simulation and Validation, Thin-Walled Structures,” vol. 46, no. 7-9, pp. 947-962, 2008.

11. Degenhardt, R., et al., "Investigations on Imperfection Sensitivity and Deduction of Improved Knockdown Factors for Unstiffened CFRP Cylindrical Shells, Composite Structures,” vol. 92, no. 8, pp.1939-1946, 2010.

12. "Space Engineering - Buckling of Structures,” European Cooperation for Space Standardization, Handbook ECSS-E-HB-32-24A, ECSS Secretariat, ESA-ESTEC Requirements and Standards Division, March 2010.

13. Lovejoy, Andrew E., Chunchu, Prasad B., and Hilburger, Mark W., "Ares-V Design Study: The Effects of Buckling Knockdown Factors, Internal Pressure, and Materials,” NASA/TM-2011-217061, February, 2011.

14. Lovejoy, Andrew E., Chunchu, Prasad B., and Hilburger, Mark W., “Ares-I Upper Stage Design Study: The Effects of Buckling Knockdown Factors and Internal Pressure,” NASA/TM-2010-216848, October, 2010.

15. Lovejoy, Andrew E., Hilburger, Mark W., and Chunchu, Prasad B, "Effects of Buckling-Knockdown Factor, Internal Pressure and Material on the Design of Stiffened Cylinders,” AIAA-2010-2778, 51st 
AIAA/ASME/ASCE/AHS/ASC Structures, Structural Dynamics, and Materials Conference, Orlando, Florida, April 12-15, 2010.

16. Hilburger, M.W., Starnes, J.H., Jr., "Effects of Imperfections on the Buckling Response of Compression-Loaded Composite Shells,” International Journal of Non-Linear Mechanics, vol. 37, no. 4-5, pp. 623-643, 2002. 